\title{
The Association between Diabetes Mellitus and Serum Prostate-Specific Antigen Levels
}

\author{
Waleed Nassar Jaffal ${ }^{1}$, Mahir Ali Al-Talah², Alaa Al-Deen Al-Dabbagh ${ }^{3}$, Ehab Jasim Mohammad ${ }^{4}$ \\ ${ }^{1}$ Ass. Professor, FICMS, College of Medicine, University of Anbar, Anbar, Iraq, ${ }^{2}$ Ass. Professor, FICMS, \\ Department of medicine, College of Medicine, University of Anbar, Anbar, Iraq, ${ }^{3}$ Ass. Professor, FICMS, College \\ of Medicine, Mustansiriyah University, Baghdad, Iraq, ${ }^{4}$ Professor, FEBU, FICMS, Head of department of Surgery. \\ College of Medicine, Ibn Sina University of Medical and Pharmaceutical Sciences, Baghdad, Iraq
}

\begin{abstract}
Background: Diabetic patients were indicated to have an improved risk for cancers of the liver, pancreas, and colon; nevertheless, recently many studies have suggested that diabetes mellitus (DM) decreased possibility for developing the cancer of prostate in men.

Objective: To analyze if the levels of prostate-specific antigen (PSA) in serum of men with type two DM were low in comparison with healthy group, and to investigate the factors that could influence the PSA level in diabetic patients.

Method: 120 diabetic men patients were analyzed for PSA levels in the serum compared with equal number age-matched control group. The relationships between the serum PSA levels and body mass index (BMI), age, hypertension, smoking and glycosylated hemoglobin (HbAlc) were considered.

Results: Serum PSA levels were statistically significantly $(\mathrm{p}<0.05)$ lower in diabetic patients compared to healthy men. The present study demonstrated that age, BMI and high HbAlc showed independent determining factors of the PSA level in men.

Conclusions: Our study strongly support that DM has inverse relationship with the levels of PSA marker and more severe cases of diabetes mellitus, older age and high body mass index in diabetic patients are associated with lower levels of the serum PSA. This result confirms that diabetes mellitus is a protective factor for prostate cancer among populations.
\end{abstract}

Keywords: Diabetes mellitus, PSA, prostate cancer.

\section{Introduction}

Diabetes mellitus (DM) and various cancers are commonly diagnosed in the same persons ${ }^{(1)}$, which suggest that the two diseases may have common risk factors and pathogenesis. The possible links include insulin resistance, hyperinsulinemia, hyperglycemia, oxidative stress, and chronic inflammation; which are factors that have potential promoting effect on the progression of cancer in many ways ${ }^{(2,3)}$.

Many studies have stated that patients with diabetes mellitus are at high risk of many types of cancers, including liver and pancreatic cancers, and the two organs have a major role in the pathogenesis of diabetes mellitus $^{(4)}$.

Different studies consistently report type two diabetes mellitus is inversely related the cancer of the prostate $^{(5,6)}$, but not all studies have reached to this conclusion $^{(7)}$.

The mechanisms for these paradoxical associations are not clear. Several studies reported that increased duration since diagnosis of type two DM decreases the risk of prostate cancer ${ }^{(8)}$ and there is some suggestion that prostate cancer risk is increased in the years immediately after the diagnosis of $\mathrm{DM}^{(6,9)}$. 
Measuring the PSA is the most useful available tumor marker for the diagnosis of the cancer of the prostate $^{(10)}$. It is commonly used for screening of the cancer of the prostate cancer ${ }^{(11)}$.

Although there are variable recommendations, the age of 50 years is suggested by several organizations for PSA screening ${ }^{(12)}$.

\section{Method}

The study was conducted on 120 previously diagnosed type 2 diabetic men with age ranging from 38 70 years old and 120 age matched normal healthy control men. Patients with type $2 \mathrm{DM}$ were selected from the diabetic clinic and outpatient clinics of urosurgery with no urological disease that may affect the PSA level at Al-Ramadi teaching hospital and Al-Yarmook teaching hospital, and the controls were healthy volunteers, between October 2016 and April 2018. Type two DM was diagnosed according to the American Diabetes Association (ADA) criteria for the diagnosis of diabetes $2010^{(13)}$

The controls should be never diagnosed with type 2 diabetes. A written consent was taken and ethical approval was obtained from Al-Anbar Medical college ethics committee.

The collection of data were based on structured questionnaires.

Men with evident prostatic disease (like prostate cancer, benign prostatic hypertrophy and prostatitis) and men with history of type $1 \mathrm{DM}$ were excluded from this study.
The hemoglobin A1c (HbAlc) was used as a marker of glycemic control. Its level is used as indicator of glycemic control within the past 3 months ${ }^{(14)}$. The HbAlc levels less or equal $6 \%$ was considered normal and $6.1 \%$ to $7 \%$ as high, and we used $6.1 \%$ as cutoff value, which was adopted by Bennett et al. (15) to diagnose patients with diabetes mellitus. The height and weight were measured to calculate the patient's BMI, BMI of $<25$ was considered as normal weight, BMI of $>25$ and $<30$ as overweight, and BMI of $>30$ as obese ${ }^{(16)}$. Waist circumference was also measured.

The blood samples were used for the measurement of the PSA and HbAlc. The PSA levels were measured using Minividas Machine using its costume kit. HbA1c analyses were done (NycoCard $\left.{ }^{\mathrm{TM}} \mathrm{HbA1c}\right)$. All measurements were done at Al-Ramadi Teaching Hospital Laboratory according to the instructions of the manufacturer.

Statistical Analysis: ANOVA test was used to analyze the statistical differences between group means and McNemar's test for comparison of proportions, also chi square was used for comparing categorical variables. Statistical analysis was performed using the Statistical Package for Social Sciences (SPSS version 24) software.

\section{Results}

The age of subjects enrolled in this study ranged from 38 to 70 years with mean of 61.59 and 60.20 year in cases and in control group respectively, there was no significant statistical difference between the age, the prevalence of smoking and family history of prostatic cancer among the two groups. Table (1).

Table (1) Characteristic of study groups.

\begin{tabular}{|l|c|c|c|}
\hline \multirow{2}{*}{ Variable } & \multicolumn{2}{|c|}{ Groups } & \multirow{2}{*}{ P value } \\
\cline { 2 - 4 } & Cases & Controls & 0.249 \\
\hline Mean age/years \pm SD & $61.59 \pm 8.97$ & $60.20 \pm 9.68$ & \\
\hline Age distribution N/\% & & & 0.847 \\
$<50$ & $15 / 12.5$ & $17 / 14.2$ & 0.847 \\
$50-59$ & $40 / 33.4$ & $38 / 31.7$ & 1.000 \\
$>60$ & $65 / 54.16$ & $65 / 54.16$ & 0.001 \\
\hline Body Mass Index/(kg/m2) \pm SD & $25.34 \pm 2.48$ & $24.19 \pm 2.62$ & \\
\hline Body mass index distribution N/\% & & & \\
$<25$ & $16 / 13.4$ & $75 / 62.5$ & 0.000 \\
$25-30$ & $59 / 49.2$ & $34 / 28.4$ & 0.002 \\
$>30$ & $45 / 37.5$ & $11 / 9.2$ & 0.000 \\
\hline
\end{tabular}




\begin{tabular}{|l|c|c|c|}
\hline \multirow{2}{*}{ Variable } & \multicolumn{2}{|c|}{ Groups } & \multirow{2}{*}{ P value } \\
\cline { 2 - 4 } & Cases & Controls & 0.333 \\
\hline Smokers N/\% & $44 / 36.7$ & $52 / 43.4$ & 0.000 \\
\hline Hypertensive N/\% & $71 / 59.2$ & $37 / 30.8$ & 0.949 \\
\hline Family history of prostate cancer N/\% & $9 / 7.5$ & $8 / 6.6$ & 0.000 \\
\hline Hb A1C(\%) \pm SD & $7 \pm 1.50$ & $4.9 \pm 0.99$ & 0.000 \\
\hline Mean PSA(ng/ml) \pm SD & $1.122 \pm 0.118$ & $1.400 \pm 0.142$ & \multirow{2}{*}{0} \\
\hline
\end{tabular}

There was a highly significant statistical difference in the mean PSA level among the three studied age groups of cases, while no statistical difference among the controls. Independent to other factors the BMI was inversely related to the mean PSA level in both groups with statistically significant difference. Table (2).

Table-(2) The association of BMI and age with mean PSA in both groups

\begin{tabular}{|c|c|c|c|c|c|c|}
\hline Variables & Csaes (N) & $\begin{array}{c}\text { Mean PSA } \\
(\mathrm{ng} / \mathrm{ml}) \pm \mathrm{SD}\end{array}$ & $P$ value & Controls & $\begin{array}{c}\text { Mean PSA } \\
(\mathrm{ng} / \mathrm{ml}) \pm \mathrm{SD}\end{array}$ & $P$ value \\
\hline $\begin{array}{l}\text { Body mass index }\left(\mathrm{kg} / \mathrm{m}^{2}\right) \\
<25 \\
25-30 \\
>30\end{array}$ & $\begin{array}{l}16 \\
59 \\
45\end{array}$ & $\begin{array}{l}1.260 \pm 0.089 \\
1.126 \pm 0.105 \\
1.067 \pm 0.102\end{array}$ & $\begin{array}{l}0.000 \\
0.000\end{array}$ & $\begin{array}{l}75 \\
34 \\
11\end{array}$ & $\begin{array}{l}1.437 \pm 0.133 \\
1.367 \pm 0.127 \\
1.245 \pm 0.121\end{array}$ & $\begin{array}{l}0.039 \\
0.000\end{array}$ \\
\hline $\begin{array}{l}25-30 \\
>30\end{array}$ & $\begin{array}{l}59 \\
45\end{array}$ & $\begin{array}{l}1.126 \pm 0.105 \\
1.067 \pm 0.102\end{array}$ & 0.018 & $\begin{array}{l}34 \\
11\end{array}$ & $\begin{array}{l}1.367 \pm 0.127 \\
1.245 \pm 0.121\end{array}$ & 0.029 \\
\hline $\begin{array}{l}\text { Age distribution/years } \\
<50 \\
50-59 \\
>60\end{array}$ & $\begin{array}{l}15 \\
40 \\
65\end{array}$ & $\begin{array}{l}1.230 \pm 0.106 \\
1.138 \pm 0.123 \\
1.080 \pm 0.101\end{array}$ & $\begin{array}{l}0.025 \\
0.000\end{array}$ & $\begin{array}{l}17 \\
38 \\
65\end{array}$ & $\begin{array}{l}1.376 \pm 0.152 \\
1.392 \pm 0.136 \\
1.411 \pm 0.143\end{array}$ & $\begin{array}{l}0.932 \\
0.678\end{array}$ \\
\hline $\begin{array}{l}50-59 \\
>60\end{array}$ & $\begin{array}{l}40 \\
65\end{array}$ & $\begin{array}{l}1.138 \pm 0.123 \\
1.080 \pm 0.101\end{array}$ & 0.034 & $\begin{array}{l}38 \\
65\end{array}$ & $\begin{array}{l}1.392 \pm 0.136 \\
1.411 \pm 0.143\end{array}$ & 0.815 \\
\hline
\end{tabular}

The mean PSA was not statistically different in smokers compared to nonsmokers in the cases but was lower in smokers compared to nonsmokers in the controls with statistically significant difference. Table (3)

Table (3) The association of Hypertension and smoking history with mean PSA in both groups.

\begin{tabular}{|l|c|c|c|c|c|c|}
\hline Variables & Cases (N) & $\begin{array}{c}\text { Mean PSA } \\
(\mathbf{n g} / \mathbf{m l}) \pm \text { SD }\end{array}$ & P value & Controls(N) & $\begin{array}{c}\text { Mean PSA } \\
\text { (ng/ml) } \pm \text { SD }\end{array}$ & P value \\
\hline Smoking state & & & & & & \\
Smoker & 44 & $1.118 \pm 0.117$ & 0.778 & 62 & $1.342 \pm 0.136$ & 0.000 \\
Non smoker & 76 & $1.124 \pm 0.119$ & & & & \\
\hline Hypertensive state & & & & 37 & $1.475 \pm 0.111$ & \\
Hypertensive(N) & 71 & $1.119 \pm 0.120$ & 0.801 & 83 & $1.395 \pm 0.145$ & 0.580 \\
Non hyprtensive(N) & 49 & $1.125 \pm 0.118$ & & & \\
\hline
\end{tabular}

Regarding duration of DM, no significant difference. Table (4). 
Table (4) The association of duration of diabetes mellitus and HbA1c with the mean PSA level in cases group.

\begin{tabular}{|l|c|c|c|}
\hline Variables & Number & Mean PSA(ng/ml) \pm SD & P value \\
\hline Hb A1C(\%) & & & \\
$\leq 6$ (Normal) & 30 & $1.232 \pm 0.108$ & 0.000 \\
$6.1-7$ (High) & 47 & $1.109 \pm 0.120$ & 0.000 \\
$>7$ (Very high) & 43 & $1.023 \pm 0.0869$ & \\
\hline $6.1-7$ & 47 & $1.109 \pm 0.120$ & 0.001 \\
$>7$ & 43 & $1.023 \pm 0.0869$ & \\
\hline Duration of DM (Years) & 33 & $1.127 \pm 0.120$ & 0.978 \\
$0-5$ & 47 & $1.122 \pm 0.119$ & 0.889 \\
$6-10$ & 40 & $1.114 \pm 0.118$ & \\
$>10$ & 47 & $1.122 \pm 0.119$ & 0.963 \\
\hline $6-10$ & 40 & $1.114 \pm 0.118$ & \\
$>10$ & \multicolumn{2}{|}{} \\
\hline
\end{tabular}

\section{Discussion}

The cancer of the prostate is the second most frequently diagnosed cancer of men and the sixth most common cause of cancer mortality among men worldwide ${ }^{(17)}$. In most Asian Countries, the incidence of cancer of the prostate has increased during the last two decades ${ }^{(18)}$.

Saad et al. have suggested a mechanism for the occurrence and progression of type two DM consisting of two-parts ${ }^{(19)}$.

Testosterone is varied by the status of DM and its duration and prostate cancer is the only cancer that is believed to be fueled by testosterone.

Another hypothesis adopted recently is related to microvascularization, of the prostate, where the damage to the blood vessels of the prostate, as a part of DM complications, prevents the development of prostate cancer ${ }^{(20)}$.

Shi et al., demonstrated that the blood level of insulin-like growth factor-I was more in patients with prostate cancer than in controls ${ }^{(21)}$.

So, in the early stage of abnormal metabolism of glucose and development of type two DM (the step of insulin resistance), the risk of the cancer of the prostate may be increased due to elevated levels of insulin and this is consistent with many studies that have examined the risk of the cancer of the prostate and duration of diabetes mellitus since the diagnosis ${ }^{(22)}$ which have found an increased risk in the early stage followed by inverse association in the later stage.

Our results are largely consistent with other study ${ }^{(23)}$ that found there was no significant difference by duration of DM.

However, the duration of diabetes mellitus is a parameter which is difficult to be determined because $50 \%$ of patients with type two diabetes mellitus may be undiagnosed ${ }^{(24)}$, and the estimated duration of diabetes mellitus may be related to the degree of medical follow up.

It is well known that as increasing ages, the PSA level will naturally increases by about $3.2 \%$ per year ${ }^{(25)}$. Richardson and Oesterling suggested age-specific reference ranges for the serum PSA level in men of different races after reviewing multiple studies ${ }^{(25)}$.

In controls, our results shows that the serum PSA level was found to be significantly increased with age and it is consistent with various Asian populations based studies conducted among China, south India, Korea, Singapore, and Japan ${ }^{(26)}$, while in diabetics as the age increased, the mean PSA level was decreased especially among men aged 60 and over, which similar to that reported by Ainahi et al. ${ }^{(27)}$.

Despite of statistically non-significant relationship between BMI and the PSA level seen in a smaller-scale study ${ }^{(28)}$, Our findings in both cases and controls are 
consistent with the findings of an inverse association between BMI and the PSA levels, where there is $5 \%$ to $21 \%$ decrease in the PSA value in men with BMI more than 30 in comparison with men with normal BMI as seen in several large-scale studies ${ }^{(29)}$. The relevant reduction in the PSA level might be attributable to increased volume of the plasma found in the larger men $^{(29)}$ or due to less androgen levels seen in the obese and insulin resistant adult males ${ }^{(30)}$.

Our findings are also consistent with the results of studies that examine the association with glycemic control in patients with T2DM. Müller et al reported that the serum PSA level is $15 \%$ and $29 \%$ lower in patients with $\mathrm{HbA} 1 \mathrm{c}$ of $6.1-6.9 \%$ and $\geq 7 \%$ respectively, in comparison with those with normal HbAlc $(<6.1 \%)^{(31)}$.

Ohwaki et al suggest a positive association between $\mathrm{HbA} 1 \mathrm{c}$ and the PSA(5.7\% increase in the PSA for each unit $\mathrm{HbAlc}$ change), which is in contrast to many studies and our current study ${ }^{(32)}$.

Similar to previous studies that reported the PSA level were significantly lower in smokers in comparison to non-smokers men who are over the age of $55^{(33)}$. We found the PSA level was significantly lower as compared with never smokers in the controls. In patients with diabetes mellitus, the PSA levels were mildly lower in smokers in comparison to non-smokers, but it was statistically nonsignificant.

Among the possible explanations for lower PSA levels in patients with type 2 diabetes mellitus is hypertension $^{(34)}$, and this is inconsistent with our results.

Ethical Clearance: The Research Ethical Committee at scientific research by ethical approval of both MOH and MOHSER in Iraq.

Conflict of Interest: Non

Funding: Self-funding

\section{References}

1. Onitilo AA, Engel JM, Glurich I, Stankowski RV, Williams GM, Doi SA. Diabetes and cancer I: risk, survival, and implications for screening. Cancer Causes Control. 2012;23:967-981.

2. Reaven GM. Insulin resistance, the insulin resistance syndrome, and cardiovascular disease. Panminerva Med. 2005;47:201-210.

3. Coussens LM, Werb Z. Inflammation and cancer.
Nature. 2002;420:860-867.

4. Johnson JA, Carstensen B, Witte D, Bowker SL, Lipscombe L, Renehan AG; Diabetes and Cancer Research Consortium. Diabetes and cancer (1): evaluating the temporal relationship between type 2 diabetes and cancer incidence. Diabetologia. 2012;55:1607-1618.

5. Bonovas S, Filioussi K, Tsantes A. Diabetes mellitus and risk of prostate cancer: a meta-analysis. Diabetologia. 2004;47:1071-1078

6. Deng D, Yang Y, Tang X, et al. Association between metformin therapy and incidence, recurrence and mortality of prostate cancer: evidence from a metaanalysis. Diabetes Metab Res Rev. 2015;31:595602.

7. Steenland K, Nowlin S, Palu S: Cancer incidence in the National Health and Nutrition Survey I. Followup data: diabetes, cholesterol, pulse and physical activity. Cancer Epidemiol Biomarkers Prev. 1995, 4:807-811.

8. Tavani A, Gallus S, Bosetti C, Tzonou A, Lagiou P, Negri E, Trichopoulos D, La Vecchia C: Diabetes and the risk of prostate cancer. Eur J Cancer Prev. 2002, 11:125-128.

9. Danker R, Boffetta P, et al. Diabetes, prostate cancer screening and risk of low- and high-grade prostate cancer: An 11 year historical population follow-up study of more than 1 million men. Diabetologia. Aug 2016; 59(8), 1683-91.

10. Stephan C, XU C, Cammann H, Graefen M, Haese A, Huland H, et al. Assay-specific artificial neural networks for five different PSA assays and populations with PSA 2-10 in 4,48 men. World J Urol. 2007; 25(1):95-103.

11. Mottet N, Bellmunt J, Bolla M, et al. EAUESTRO-SIOG Guidelines on Prostate Cancer. Part 1: Screening, Diagnosis, and Local Treatment with Curative Intent. Eur Urol. 2017;71:618-629.

12. Harris R, Lohr KN. Screening for prostate cancer: an update of the evidence for the U.S. Preventive Services Task Force. Ann Intern Med. 2002;137:917-929.

13. Diagnosis and classification of diabetes mellitus. Diabetes Care. 2010 Jan. 33 Suppl 1:S62-69.

14. Nathan DMSD, Hurxthal K, Goodson JD. Clinical value of the glycosylated hemoglobin assay. $\mathrm{N}$ Engl J Med 1984;310:1746 - 1747. 
15. Bennett CM, Guo M, Dharmage SC. $\mathrm{HbA}(1 \mathrm{c})$ as a screening tool for detection of type 2 diabetes: a systematic review. Diabet Med. 2007;24:333 343.

16. Bonn SE, Sjölander A, Tillander A, Wiklund F, Grönberg H, Bälter K, et al. Body mass index in relation to serum prostate-specific antigen levels and prostate cancer risk. Int J Cancer. 2016;139:5057.

17. Center MM, Jemal A, Lortet-Tieulent J, et al. International variation in prostate cancer incidence and mortality rates. Eur Urol. 2012;61:1079- 1092.

18. Pu YS, Chiang HS, Lin CC, Huang CY, Huang $\mathrm{KH}$, Chen J. Changing trends of prostate cancer in Asia. Aging Male. 2004; 7: 120-132.

19. Saad MF, Knowler WC, Pettitt DJ, et al. A two-step model for development of non-insulin-dependent diabetes. Am J Med. 1991;90:229 - 235.

20. Zhang $\mathrm{W}, \mathrm{Hu} \mathrm{R}$. Why does diabetes offer protective effects against prostate cancer? The possible role of its microvascular complications. Med Hypotheses. 2010;74:242-3.

21. Shi R, Berkel HJ, Yu H. Insulin-like growth factor-I and prostate cancer: a meta-analysis. Br J Cancer. 2001;85:991 -996.

32. Rodriguez C, Patel AV, Mondul AM, et al. Diabetes and risk of prostate cancer in a prospective cohort of US men. Am J Epidemiol. 2005;161:147 - 152.

23. Will JC, Vinicor F, Calle EE. Is diabetes mellitus associated with prostate cancer incidence and survival? Epidemiology. 1999;10:313-318.

24. Rathmann W, Haastert B, Icks A, et al. High prevalence of undiagnosed diabetes mellitus in Southern Germany: target populations for efficient screening. The KORA survey 2000. Diabetologia. 2003;46:182 - 189 .

25. Richardson TD, Oesterling JE. Age-specific reference ranges for serum prostate-specific antigen. Urol Clin North Am. 1997;24(2):339-351.

26. Lee SE, Byun SS, Park HK, Shim HB, Ku JH. Detection of prostate cancer at low and intermediate serum prostate-specific antigen levels in a country with a low incidence of prostate cancer. Jpn J Clin Oncol. 2006;36:376-380.

27. Ainahi A, Brakat A, Wakrim L, Mohammadi $\mathrm{H}$, ElMdaghri N, Ezzikouri S. Prostate-specific antigen levels in Moroccan diabetic males: A crosssectional study. Current diabetes reviews. 2018 Jun 1;14(3):286-90.

28. Hutterer G, Perrotte P, Gallina A, et al. Body mass index does not predict prostate-specific antigen or percent free prostate-specific antigen in men undergoing prostate cancer screening. Eur J Cancer. 2007;43(7):1180-1187.

29. Bañez LL, Hamilton RJ, Partin AW, et al. Obesity-related plasma hemodilution and PSA concentration among men with prostate cancer. Jama. 2007;298(19):2275-2280.

30. Pitteloud N, Mootha VK, Dwyer AA, et al. Relationship between testosterone levels, insulin sensitivity, and mitochondrial function in men. Diabetes Care. 2005; 28:1636.

31. Müller H, Raum E, Rothenbacher $D$, et al. Association of diabetes and body mass index with levels of prostate-specific antigen: implications for correction of prostate-specific antigen cutoff values? Cancer Epidemiology Biomarkers \& Prevention. 2009; 18:1350-1356.

32. Ohwaki K, Endo F, Muraishi O, Yano E. Relationship between changes in haemoglobin $\mathrm{A} 1 \mathrm{C}$ and prostate-specific antigen in healthy men. European journal of cancer. 2011 Jan 1;47(2):262266.

33. 'Kristal AR, Chi C, Tangen CM, et al. Associations of demographic and lifestyle characteristics with prostate-specific antigen (PSA) concentration and rate of PSA increase. Cancer. 2006;106:320-328.

34. Chang SL, Harshman LC, Presti JC. Impact of common medications on serum total prostatespecific antigen levels: analysis of the National Health and Nutrition Examination Survey. Journal of Clinical Oncology. 2010; 28:3951. 